\title{
Message from the Editor in Chief
}

\author{
O. Ortmann ${ }^{1}$
}

Published online: 22 August 2015

(C) Springer-Verlag Berlin Heidelberg 2015

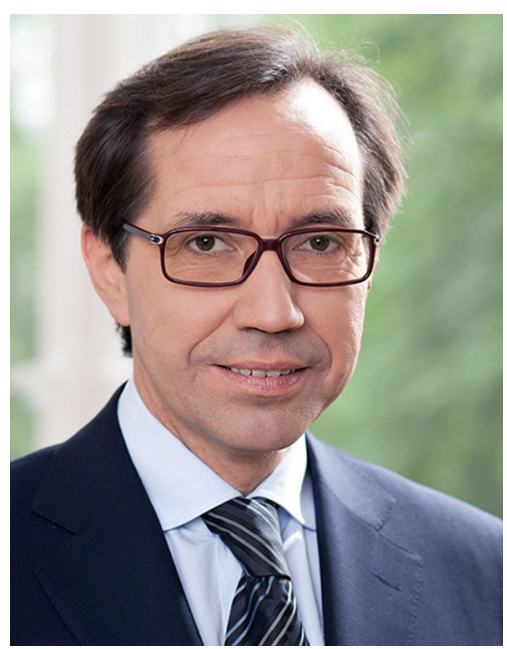

Archives of Gynecology and Obstetrics has a long and outstanding history. It was founded in 1870 as Archiv für Gynäkologie. Since 1922, it is the official journal of the German Society of Gynecology and Obstetrics (Deutsche Gesellschaft für Gynäkologie und Geburtshilfe, DGGG). The journal publishes reviews and original articles on clinical and basic research from all subspecialities in gynecology and obstetrics. The more recent history has been formed by $\mathrm{H}$. Ludwig, Basel, Switzerland and K. Diedrich, Lübeck, Germany, who served as editors in chief from 1998 to 2010 and from 2010 to 2013, respectively. Outstanding staff, editors, associate editors, editorial board members and reviewers have greatly contributed to the success of the journal. Under the

\section{O. Ortmann}

olaf.ortmann@klinik.uni-regensburg.de

1 Department of Gynaecology and Obstetrics, University Medical Center Regensburg, Caritas-Hospital St. Josef, Landshuter Straße 65, 93053 Regensburg, Germany

leadership of H. Ludwig and K. Diedrich, their outstanding work for the journal had major impact on the quality and widening of the international contributors and readership. The journal receives an increasing number of a submission in 2014 and had 1574 submissions from all over the world. Manuscripts mainly come from European countries, Asia, Middle East, North and South America. Also, the readership is international; the electronic version of the journal is worldwide disseminated and available 24/7. Currently, 9380 institutions have access to the electronic version. In the last years, editorial management has clearly improved with reduced duration of the review process and an average time of 15 days from acceptance to online first publication.

In 2015, publication of the print version was terminated and the journal is available only in an electronic version.

The improvement of quality is also demonstrated by the increase of the impact factor, which is currently 1.364.

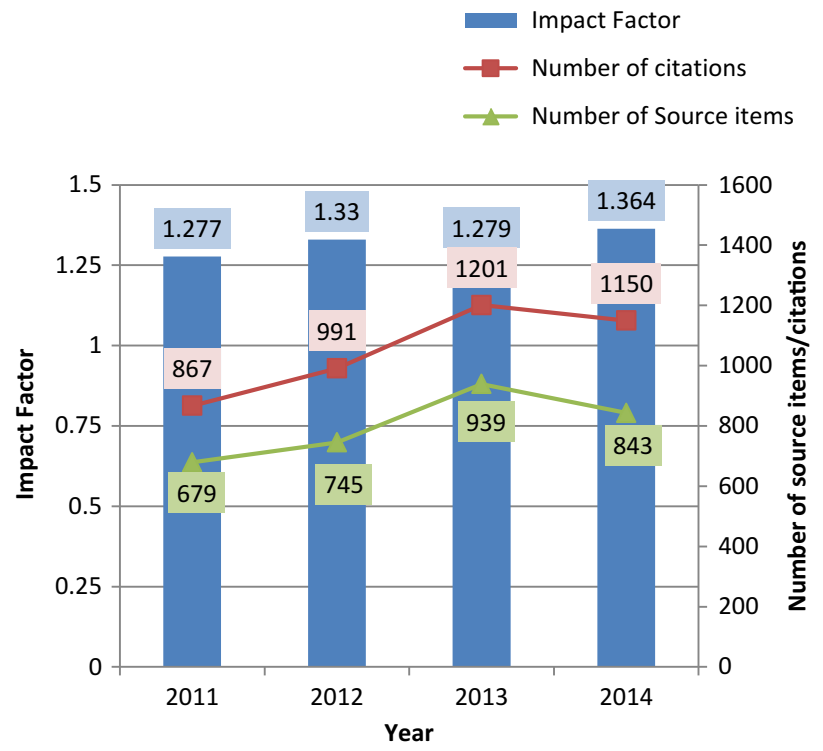


You are invited to submit manuscripts for publication in the different categories of the Journal. Please feel free to make suggestions that will improve the quality of the journal.

Prof. Dr. O. Ortmann

Editor-in-Chief

\section{Compliance with ethical standards}

Conflict of interest None. 